\title{
Effects of COVID-2019 on plastic surgery emergencies in Korea
}

\author{
Young Soo Yoon, \\ Chang Ho Chung, \\ Kyung Hee Min \\ Department of Plastic and \\ Reconstructive Surgery, Nowon Eulji \\ Medical Center, Eulji University School \\ of Medicine, Seoul, Korea
}

\begin{abstract}
Background: To fight the coronavirus disease 2019 (COVID-19) pandemic, many countries have implemented social distancing and lockdowns. We investigated the changes in the trauma patterns of emergency plastic surgeries in the midst of a pandemic.

Methods: A retrospective review of the medical records of all patients treated for emergency plastic surgeries was performed at our hospital in Seoul. We conducted the analysis between March 1 and June 30,2020, and compared the data obtained with that of the same period in 2019. We also investigated changes in trauma patterns according to the social distancing level from July 2020 to February 2021.

Results: There was a total of 800 emergency plastic surgery patients from March to June 2020, which was less than the 981 in the corresponding period in 2019. The proportion of patients aged 7-17 years and $\geq 80$ in 2020 showed a significant decrease. In 2020, patients presenting with facial trauma decreased and hand trauma, markedly laceration, increased significantly. In 2020, more injuries happened at home, whereas significantly fewer injuries happened on the streets. In 2020, slipping and sports injury decreased, whereas penetrating injury increased significantly. In the changes observed according to the social distancing level, there were significant differences in age classification, facial open wound, and the mechanism of injury.

Conclusion: Social distancing has caused a change in emergency plastic surgeries. To ensure safe and appropriate treatment, strict epidemiologic workup and protective equipment are required.
\end{abstract}

Keywords: Coronavirus / Plastic surgery / Trauma

\section{INTRODUCTION}

Since the first case of an epidemic viral pneumonia in Wuhan, China in December 2019, the infection rapidly spread. The causative virus was a novel coronavirus and was named corona-

\section{Correspondence: Kyung Hee Min}

Department of Plastic and Reconstructive Surgery, Nowon Eulji Medical Center, Eulji University School of Medicine, 68 Hangeulbiseong-ro, Nowon-gu, Seoul 01830, Korea

E-mail:mkh797@hanmail.net

This work was supported by the National research Foundation of Korea (NRF) grant funded by the Korea government (MIST; Ministry of Science and ICT) (2018R1C1B504478613).

Received February 8, 2021 / Revised April 19, 2021 / Accepted April 19, 2021 virus disease 2019 (COVID-19) [1,2]. With a high infectivity, COVID-19 spread worldwide, and as a response, the World Health Organization after all declared the infection a global pandemic on March 11, 2020 [3]. In South Korea, the number of confirmed cases of COVID-19 has risen progressively since the first confirmed case in January 2020, with 3,526 cases reported by March 1, 2020; 23,889 cases by October 1, 2020; 34,652 cases by December 1, 2020; and 96,017 cases reported by March 15, 2021. The Korean government raised the infectious disease risk to "serious" on February 23 [4]. Reopening of schools that had been scheduled on March 2, 2020, was delayed to May 20, 2020, since then, students have only partially re- 
turned to in-school classes [5]. Since June 28, 2020, predefined levels of social distancing have been implemented depending on the severity of the local COVID-19 epidemic and the intensity of quarantine measures. Level 1 is classified as standard daily life precautions; Level 1.5 to 2 is the local epidemic level; and Level 2.5 to 3 is seen as the national epidemic level. As the level of social distancing increases, participation in gatherings and use of multi-use facilities becomes progressively more restricted [4].

As shown here, the COVID-19 has led to heavy restrictions in schools, workplaces, public facilities, and shops, and the implementation of social distancing has brought upon grave changes in people's lifestyles. Health care facilities engage in stringent disinfection measures and implement visitor restrictions in an effort to respond to the COVID-19. The present study aims to compare the data on patients admitted to the emergency department, who were treated by the plastic surgery department since the outbreak of COVID-19 with the data in the same period last year, in order to examine the changes caused by COVID-19. In addition, as social distancing was implemented, we attempted to determine whether there was any change in the profile of plastic surgery trauma patients according to the social distancing level.

\section{METHODS}

We retrospectively analyzed the data from the medical records of all patients treated for emergency plastic surgeries at the emergency medicine department of our hospital, between March 1 and June 30, 2020. Additionally, this data was compared to that obtained from the same period in 2019. Plastic surgery patients who visited the emergency room from July 2020 when social distancing began to be implemented by level, to February 2021, were analyzed to determine whether there was a difference in the pattern of plastic surgery according to the level of social distancing. The social distancing level was divided into 3 stages: Stage 1, daily life precautions (Level 1); Stage 2, local epidemic level (Level 1.5 to 2); and Stage 3, national epidemic level (Level 2.5 to 3). In the statistical analysis, the periods were matched and compared at each stage. The medical records were analyzed for factors such as age, sex, region of injury, type of injury, mechanism of injury, presence of domestic violence, location where injury had occurred, and admission status.

Statistical analysis was performed using SPSS 26.0 (IBM Corp., Armonk, NY, USA). Pearson chi-square test and Fisher exact test were utilized to investigate the differences between the variables. Student $t$-test was used to investigate quantitative parameters. A $p$-value $<0.05$ was considered statistically significant.
The study was approved by the Institutional Review Board of our hospital (IRB No. 2020-08-007).

\section{RESULTS}

A total of 981 patients were treated for emergency plastic surgery between March 1 and June 30, 2019. On the other hand, during the same period in 2020, the total number of patients had decreased to 800 . There was no significant difference in the mean age and sex of the patients between both periods. When age was analyzed by section, the proportion of patients aged $7-17$ years and $\geq 80$ years showed a significant decrease in 2020 , compared to those in $2019(p<0.000)$.

In 2020 , facial trauma decreased and hand trauma increased significantly compared to that in $2019(p<0.000)$. Among facial trauma, open wounds and contusions were significantly reduced whereas in regard to hand trauma, laceration increased significantly. However, there was no significant difference observed in burns and animal bites between the two periods. In 2020, when compared to 2019, a significant difference was observed whereby more injuries took place at home and fewer injuries were seen on the streets $(p<0.000)$. Regarding the mechanism of injury in 2020, as compared to 2019, slip down and sports injury decreased, whereas penetrating injury increased significantly $(p<0.000)$. Assault injury and domestic violence were not significantly different between the two periods. The patient on admission was not significantly different between the two periods (Table 1).

While analyzing burn patients, no significant difference was observed between the two periods, in factors such as, the total number of patients, sex, age, location where burn occurred, and mechanism of burn. However, in 2020, burns-related injuries were observed more in women than in men, and burns at home increased whereas burns at work or school decreased, when compared to that in 2019. However, there was no significant difference observed (Table 2).

The level of social distancing in Seoul started at Level 1 on June 28, 2020 and subsequently increased by several levels. During the period investigated in this study, social distancing was at Stage 1 for 84 days, at Stage 2 for 75 days, and at Stage 3 for 84 days (Fig. 1) [4]. In the comparison between stages, there were significantly fewer patients aged 7 to 17 years during Stage 3 and significantly fewer patients aged 18 to 65 years during Stage 2. During Stage 1, the incidence of facial open wounds was significantly lower than during the other stages. The incidence of sports-induced trauma was significantly higher during Stage 1, while the incidence of bump-induced trauma (trauma caused by collision with an object) was significantly higher dur- 
Table 1. Characteristics of patients

\begin{tabular}{|c|c|c|c|}
\hline \multirow{2}{*}{ Characteristics } & \multicolumn{2}{|c|}{ Period } & \multirow{2}{*}{$p$-value } \\
\hline & $2019(03 / 01-06 / 30)$ & $2020(03 / 01-06 / 30)$ & \\
\hline Total patients & 981 & 800 & \\
\hline Sex & & & 0.861 \\
\hline Male & $576(58.7)$ & $473(59.1)$ & \\
\hline Female & $405(41.3)$ & $327(40.9)$ & \\
\hline Age (yr) & $36.05 \pm 25.22$ & $35.77 \pm 23.63$ & 0.812 \\
\hline Age classification (yr) & & & 0.000 \\
\hline $0-6$ & $169(17.2)$ & $154(19.3)$ & \\
\hline $7-17$ & $136(13.9)$ & $64(8.0)$ & \\
\hline $18-65$ & $535(54.5)$ & $497(62.1)$ & \\
\hline $66-79$ & $87(8.9)$ & $71(8.9)$ & \\
\hline$\geq 80$ & $54(5.5)$ & $14(1.8)$ & \\
\hline Face & $578(58.8)$ & $391(48.9)$ & 0.000 \\
\hline Open wound & $433(44.1)$ & $295(36.9)$ & 0.002 \\
\hline Contusion & $106(10.8)$ & $56(7.0)$ & 0.005 \\
\hline Fracture & $39(4.0)$ & $40(5.0)$ & 0.296 \\
\hline Hand & $274(28.0)$ & $305(38.0)$ & 0.000 \\
\hline Laceration & $250(25.5)$ & $288(36.0)$ & 0.000 \\
\hline Tendon injury & $4(0.4)$ & $1(0.1)$ & 0.262 \\
\hline Fracture & $20(2.0)$ & $16(2.0)$ & 0.954 \\
\hline Burn & $64(6.5)$ & $58(7.2)$ & 0.546 \\
\hline Animal bite & $62(6.3)$ & $38(4.8)$ & 0.152 \\
\hline Location at time of injury & & & 0.000 \\
\hline Home & $422(43.0)$ & $441(55.1)$ & \\
\hline Work (school) & $92(9.4)$ & 85 (10.6) & \\
\hline Street & $401(40.9)$ & $233(29.1)$ & \\
\hline Bar & $58(5.9)$ & $38(4.8)$ & \\
\hline Others & $8(0.8)$ & $3(0.4)$ & \\
\hline Mechanism of injury & & & 0.000 \\
\hline Assault & $45(5.3)$ & $37(5.3)$ & \\
\hline Domestic violence & $4(0.4)$ & $6(0.8)$ & 0.359 \\
\hline Slip down & 279 (32.6) & $170(24.1)$ & \\
\hline Sports & $57(6.7)$ & $24(3.4)$ & \\
\hline Motor vehicle collisions & $28(3.3)$ & $32(4.5)$ & \\
\hline Penetrating & $209(24.4)$ & $261(37.1)$ & \\
\hline Bump & $219(25.6)$ & $161(22.9)$ & \\
\hline Fall & $18(2.1)$ & $19(2.7)$ & \\
\hline Admission & $12(1.2)$ & $12(1.5)$ & 0.614 \\
\hline
\end{tabular}

Values are presented as number (\%) or mean \pm SD.

ing Stage 3. There were no other statistically significant differences in the results between stages (Tables 3,4 ).

\section{DISCUSSION}

Owing to the rapid spread of COVID-19, social distancing and region-wide lockdowns have been implemented globally, with
Table 2. Characteristics of burn patients

\begin{tabular}{|c|c|c|c|}
\hline \multirow{2}{*}{ Characteristics } & \multicolumn{2}{|c|}{ Period } & \multirow{2}{*}{$p$-value } \\
\hline & $2019(03 / 01-06 / 30)$ & $2020(03 / 01-06.30)$ & \\
\hline Total patients & $64(6.5)$ & $58(7.2)$ & 0.546 \\
\hline Sex & & & 0.251 \\
\hline Male & $32(50.0)$ & $23(39.7)$ & \\
\hline Female & $32(50.0)$ & 35 (60.3) & \\
\hline Age (yr) & $30.8 \pm 21.62$ & $31.29 \pm 20.52$ & 0.811 \\
\hline Age classification (yr) & & & 0.835 \\
\hline $0-6$ & $11(17.2)$ & $11(19.0)$ & \\
\hline $7-17$ & $7(10.9)$ & $6(10.3)$ & \\
\hline $18-65$ & $42(65.6)$ & $40(69.0)$ & \\
\hline $66-79$ & $2(3.1)$ & $1(1.7)$ & \\
\hline$\geq 80$ & $2(3.1)$ & 0 & \\
\hline Location at time of burn & & & 0.171 \\
\hline Home & $48(75.0)$ & 48 (82.8) & \\
\hline Work (school) & $12(18.8)$ & $4(6.9)$ & \\
\hline Street & $2(3.1)$ & $3(5.2)$ & \\
\hline Bar & 0 & $2(3.4)$ & \\
\hline Others & $2(3.1)$ & $1(1.7)$ & \\
\hline Mechanism of burn & & & 0.856 \\
\hline Scald & 45 (70.3) & 38 (65.5) & \\
\hline Contact & $17(26.6))$ & 17 (29.3) & \\
\hline Electric & $1(1.6)$ & $2(3.4)$ & \\
\hline Flame & $1(1.6)$ & $1(1.7)$ & \\
\hline
\end{tabular}

Values are presented as number (\%) or mean \pm SD.

people's living patterns being forced to change.

In Anhui Province in eastern, China, the number of traffic-related injuries along with outdoor injuries showed a significant decrease during the peak of the pandemic [6]. In Salisbury District Hospital in southwest England, during the lockdown period, there was a drop in the number of trauma patients [7]. Additionally, in Mexico City, during the COVID-19 lockdown, plastic surgery-related emergency procedures were reduced by $65 \%$ [8]. Hassan et al. [9] reported that during stay-at-home orders, in Chicago, emergency plastic surgeries were significantly decreased with a marked decrease in hand traumas. In addition, our results showed that the number of patients treated with emergency plastic surgeries decreased between March 1 and June 30, 2020, compared to the same period in 2019 (800 vs. 981). The number of patients with facial trauma decreased significantly. In addition, the pattern of facial trauma changed: whereas lacerations and contusions significantly decreased, there was no significant difference in the number of fractures. This is likely to be because individuals with relatively minor trauma did not visit the emergency department because of difficulty with accessing the hospital and individuals' reluctance to visit the hospital due to COVID-19. Similar to other studies, in 


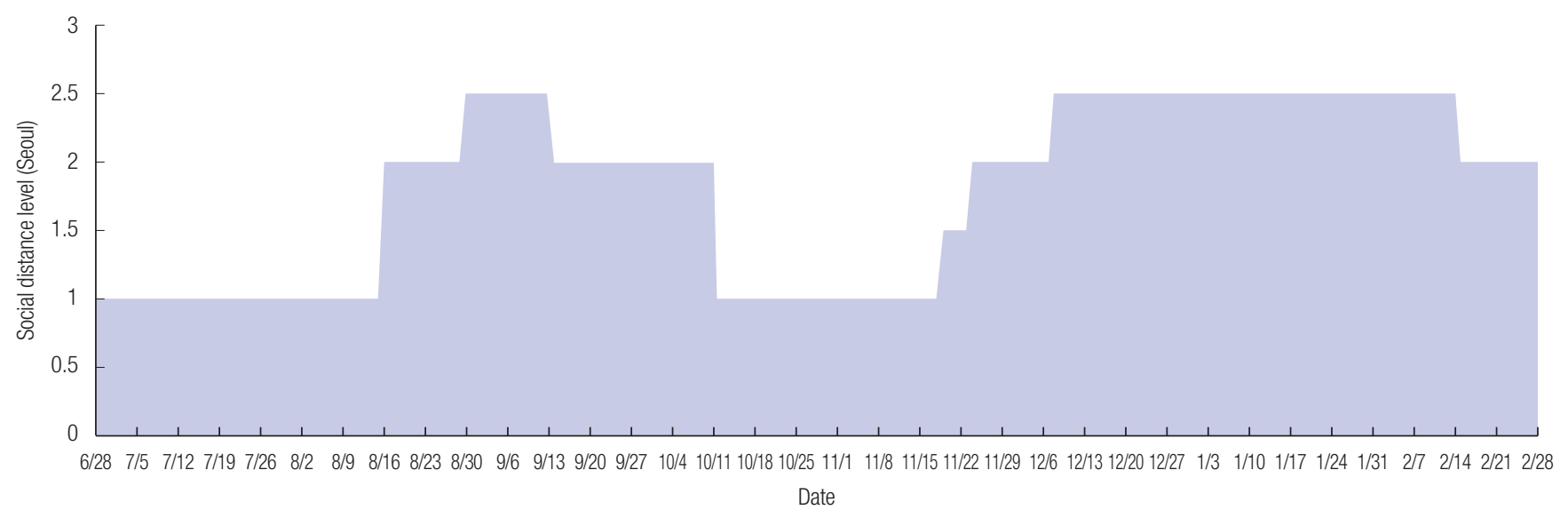

Fig. 1. Changes in the social distancing level in Seoul from June 28, 2020 to February 28, 2021 [4].

our study, the number of injuries at home increased and those on the streets decreased. However, there was no decrease in the number of traffic injuries observed in our results. Unlike the findings of Hassan et al. [9], our results revealed that hand-related trauma, especially laceration, increased significantly, while facial trauma had significantly decreased. This can be attributed to an increase in activities at home, such as cooking, as the time spent at home had increased.

In Chicago, Illinois, domestic violence-related calls had increased by $12 \%$ during stay-at-home [10]. Hassan et al. [9] also reported that the percentage of assault injuries, including domestic violence, had increased. However, there was no such increase observed in assault injury and domestic violence in our results. In our results, the number of school-going patients, aged 7-17 years, decreased significantly in 2020. We assume that this may reflect the decrease in chance of trauma due to the decrease in outdoor activities as students spend more time at home as school attendance is delayed. In addition, the number of patients aged $\geq 80$ years decreased in 2020 . This could possibly be because the elderly are aware of their vulnerability towards contracting COVID-19, resulting in them maintaining social distancing more thoroughly, and performing fewer outdoor activities. In addition to this, in our study, the characteristics of burns were not significantly different between the two periods. Kruchevsky et al. [11] reported that in northern Israel, during the lockdown period, the number of adult burn patients had decreased by $66 \%$. However, there was no decrease observed in the number of pediatric burn patients. In addition to this, children aged 2-5 years and female patients from all pediatric age groups were seen to have a higher susceptibility to burns. They suggested that a decrease in the number of adult burn patients was associated with a decrease in occupation-related burn. They also suggested an increase in kitchen and dining activities during a period of lockdown, which tend to be more likely performed by women. In our results, although not significant, in 2020, there was an increase in female patients and burn injuries at home, with a decrease in occupation- or school-related burn injuries.

In the changes observed according to the social distancing level, the incidence of sports-induced trauma was significantly higher during Stage 1 (Level 1), and the incidence of bump-induced trauma was significantly higher during Stage 3 (Level 2.5 to 3). This reflects the increased restriction of outdoor activities as the level of social distancing increased. However, the lack of a significant difference in many of the results suggests that people are adapting to changes in their daily life as the during of social distancing becomes increasingly prolonged.

Even in the midst of a serious crisis such as a pandemic, emergency plastic surgeries and traumas are inevitable. In addition, plastic surgeons, especially when managing craniofacial trau$\mathrm{ma}$, are at a greater risk of exposure to the virus as they examine and treat patients while being in close contact with their nose and mouth [12]. Therefore, strict epidemiologic investigation and monitoring of COVID-19-related symptoms in patients are very crucial.

Currently, in Korea, patients with fever or respiratory symptoms are treated in a separate clinic, and patients with symptoms suggestive of COVID-19 are required to undergoing coronavirus testing and treatment in a negative pressure isolation room, even when visiting the emergency department. Additionally, when managing suspected infections, it is necessary to install appropriate protective equipment.

To prevent trauma at home during the pandemic, it is also important to educate people about safety education and firstaid tips at home.

The limitation of our study is that our data were based on a single emergency medicine department in Seoul. It is likely that the COVID-19 epidemic has had a similar effect on emergency 
Table 3. Characteristics of patients by stage of social distancing level

\begin{tabular}{|c|c|c|c|c|}
\hline Characteristics & $\begin{array}{l}\text { Stage1 } \\
\text { (level 1) }\end{array}$ & $\begin{array}{c}\text { Stage 2 } \\
\text { (level 1.5-2) }\end{array}$ & $\begin{array}{c}\text { Stage 3 } \\
\text { (level 2.5-3) }\end{array}$ & $p$-value \\
\hline Total patients & 468 & 494 & 438 & \\
\hline Sex & & & & 0.127 \\
\hline Male & $260(55.6)$ & $298(60.3)$ & $271(61.9)$ & \\
\hline Female & $208(44.4)$ & $196(39.7)$ & $167(38.1)$ & \\
\hline Age (yr) & $37.57 \pm 24.50$ & $38.10 \pm 25.97$ & $37.99 \pm 24.88$ & 0.944 \\
\hline Age classification (yr) & & & & 0.021 \\
\hline $0-6$ & 79 (16.9) & $86(17.4)$ & $83(18.9)$ & \\
\hline $7-17$ & $46(9.8)$ & 59 (11.9) & $24(5.5)$ & \\
\hline $18-65$ & $283(60.5)$ & $263(53.2)$ & $267(61.0)$ & \\
\hline $66-79$ & $43(9.2)$ & $60(12.1)$ & $46(10.5)$ & \\
\hline$\geq 80$ & $17(3.6)$ & $26(5.3)$ & $18(4.1)$ & \\
\hline Face & $256(54.7)$ & $291(58.9)$ & $258(58.9)$ & 0.324 \\
\hline Open wound & $168(35.9)$ & $208(42.1)$ & $199(45.4)$ & 0.011 \\
\hline Contusion & $75(16.0)$ & $67(13.6)$ & $52(11.9)$ & 0.190 \\
\hline Fracture & $13(2.8)$ & $16(3.2)$ & $7(1.6)$ & 0.271 \\
\hline Hand & $156(33.3)$ & $148(30.0)$ & $120(27.4)$ & 0.148 \\
\hline Laceration & $135(28.8)$ & $132(26.7)$ & $106(24.2)$ & 0.286 \\
\hline Tendon injury & $15(3.2)$ & $11(2.2)$ & $11(2.5)$ & 0.626 \\
\hline Fracture & $6(1.3)$ & $5(1.0)$ & $3(0.7)$ & 0.665 \\
\hline Burn & $33(7.1)$ & $27(5.5)$ & $24(5.5)$ & 0.502 \\
\hline Animal bite & $21(4.5)$ & $27(5.5)$ & $36(8.2)$ & 0.050 \\
\hline Location at time of injur & & & & 0.263 \\
\hline Home & $229(50.1)$ & $240(49.3)$ & 247 (56.9) & \\
\hline Work (school) & $41(9.0)$ & 49 (10.1) & $39(9.0)$ & \\
\hline Street & $172(37.6)$ & $183(37.6)$ & $135(31.1)$ & \\
\hline Bar & $12(2.6)$ & $14(2.9)$ & $11(2.5)$ & \\
\hline Others & $3(0.7)$ & 0 & $2(0.5)$ & \\
\hline Mechanism of injury & & & & 0.004 \\
\hline Assault & $16(3.9)$ & $23(5.2)$ & $19(5.0)$ & \\
\hline Domestic violence & $5(1.1)$ & $7(1.4)$ & $5(1.1)$ & 0.873 \\
\hline Slip down & $125(30.2)$ & $149(33.8)$ & $117(30.9)$ & \\
\hline Sports & $37(8.9)$ & $17(3.9)$ & $14(3.7)$ & \\
\hline $\begin{array}{l}\text { Motor vehicle } \\
\text { collisions }\end{array}$ & $18(4.3)$ & $25(5.7)$ & $13(3.4)$ & \\
\hline Penetrating & $129(31.2)$ & $122(27.7)$ & $113(29.8)$ & \\
\hline Bump & 70 (16.9) & 83 (18.8) & 95 (25.1) & \\
\hline Fall & $8(1.9)$ & $13(2.9)$ & $4(1.1)$ & \\
\hline Admission & $28(6.0)$ & $27(5.5)$ & $24(5.5)$ & 0.926 \\
\hline
\end{tabular}

Values are presented as number (\%) or mean \pm SD.

plastic surgery consultations in other regions of Korea, but the situation may differ in hospitals around the city center and provinces, especially in hospitals around highways.

The findings of our study confirm that a change in lifestyle owing to the COVID-19 pandemic causes a change in the patterns of trauma-related emergency plastic surgeries. The COV-
Table 4. Characteristics of burn patients by stage of social distancing level

\begin{tabular}{|c|c|c|c|c|}
\hline Characteristics & $\begin{array}{l}\text { Stage1 } \\
\text { (level 1) }\end{array}$ & $\begin{array}{c}\text { Stage 2 } \\
\text { (level 1.5-2) }\end{array}$ & $\begin{array}{c}\text { Stage 3 } \\
\text { (level 2.5-3) }\end{array}$ & $p$-value \\
\hline Total patients & $33(7.1)$ & $27(5.5)$ & $24(5.5)$ & 0.502 \\
\hline Sex & & & & 0.059 \\
\hline Male & $8(24.2)$ & $12(44.4)$ & $13(54.2)$ & \\
\hline Female & $25(75.8)$ & 15 (55.6) & $11(45.8)$ & \\
\hline Age (yr) & $39.79 \pm 19.65$ & $30.85 \pm 24.11$ & $39.88 \pm 22.94$ & 0.227 \\
\hline Age classification (yr) & & & & 0.340 \\
\hline $0-6$ & $1(3.0)$ & $6(22.2)$ & $1(4.2)$ & \\
\hline $7-17$ & $4(12.1)$ & $2(7.4)$ & $2(8.3)$ & \\
\hline $18-65$ & $24(72.7)$ & $16(59.3)$ & $18(75.0)$ & \\
\hline $66-79$ & $4(12.1)$ & $2(7.4)$ & 2 (8.3) & \\
\hline$\geq 80$ & 0 & $1(3.7)$ & $1(4.2)$ & \\
\hline Location at time of burn & & & & 0.379 \\
\hline Home & $19(86.4)$ & $14(70.0)$ & $14(70.0)$ & \\
\hline Work (school) & $2(9.1)$ & $4(20.0)$ & $4(20.0)$ & \\
\hline Street & 0 & $2(10.0)$ & 0 & \\
\hline Bar & $1(4.5)$ & 0 & $1(5.0)$ & \\
\hline Others & 0 & 0 & $1(5.0)$ & \\
\hline Mechanism of burn & & & & 0.939 \\
\hline Scald & $23(69.7)$ & $19(73.1)$ & $15(65.2)$ & \\
\hline Contact & $8(24.2)$ & $6(23.1)$ & $5(21.7)$ & \\
\hline Electric & $1(3.0)$ & 0 & $1(4.3)$ & \\
\hline Flame & $1(3.0)$ & $1(3.8)$ & $2(8.7)$ & \\
\hline
\end{tabular}

Values are presented as number (\%) or mean \pm SD.

ID-19 epidemic situation is likely to change a lot in the future due to the impact of vaccination and mutant strains of the virus. Changes in the incidence and pattern of trauma are anticipated, not only because of COVID-19, but also because of other rapidly evolving social changes, such as the development of motor vehicles and machines with advanced safety features, and an increase in the use of electric scooters. To adapt to this change and to manage patients safely and appropriately, it is important that the government, hospitals, physicians, and patients cooperate with each other.

\section{NOTES}

\section{Conflict of interest}

No potential conflict of interest relevant to this article was reported.

\section{Ethical approval}

The study was approved by the Institutional Review Board of Nowon Eulji Medical Center (IRB No; 2020-08-007) and performed in accordance with the principles of the Declaration of 
Helsinki. The requirement of informed consent was waived owing to the retrospective nature of the study.

\section{ORCID}

\section{Young Soo Yoon}

Chang Ho Chung

Kyung Hee Min

https://orcid.org/0000-0003-4651-240X

https://orcid.org/0000-0002-9431-737X

https://orcid.org/0000-0002-3456-0191

\section{Author contribution}

Conceptualization: KHM. Data curation: YSY, CHC. Formal analysis: YSY, CHC. Methodology: KHM. Supervision: KHM. Writing - original draft: YSY, CHC, KHM. Writing - review \& editing: KHM.

\section{REFERENCES}

1. Li Q, Guan X, Wu P, Wang X, Zhou L, Tong Y, et al. Early transmission dynamics in Wuhan, China, of novel coronavirus-infected pneumonia. N Engl J Med 2020;382:1199-207.

2. Wang C, Horby PW, Hayden FG, Gao GF. A novel coronavirus outbreak of global health concern. Lancet 2020;395:470-3.

3. World Health Organization (WHO). WHO novel coronavirus (COVID-19) dashboard [Internet]. Geneva: WHO; c2020 [cited 2021 Apr 1]. Available from: http://www.who.int/.

4. Korea Disease Control and Prevention Agency. Coronavirus-19, Republic of Korea [Internet]. Osong: Korea Disease Control and Prevention Agency; c2021 [cited 2021 Apr 1]. Available from: http://ncov.mohw.go.kr/en/.

5. Ministry of Education. Press release [Internet]. Ministry of Ed- ucation: Sejong; c2020 [cited 2021 Apr 1]. Available from: http://english.moe.go.kr/main.do?s=english.

6. Zhu W, Li X, Wu Y, Xu C, Li L, Yang J, et al. Community quarantine strategy against coronavirus disease 2019 in Anhui: an evaluation based on trauma center patients. Int J Infect Dis 2020;96:417-21.

7. Valand P, Lloyd N, Robson M, Steele J. Trauma transformed: a positive review of change during the COVID-19 pandemic. J Plast Reconstr Aesthet Surg 2020;73:1357-404.

8. Telich-Tarriba JE, Navarro-Barquin DF. Plastic surgery emergency surgical care during the COVID-19 lockdown at a Mexico City academic center. J Plast Reconstr Aesthet Surg 2021; 74:644-710.

9. Hassan K, Prescher H, Wang F, Chang DW, Reid RR. Evaluating the effects of COVID-19 on plastic surgery emergencies: protocols and analysis from a level I trauma center. Ann Plast Surg 2020;85(2S Suppl 2):S161-S165.

10. Assad S, Hickey M. Chicago sees an uptick in domestic violence calls during coronavirus outbreak [Internet]. WBBM-TV CBS 2. Chicago, IL: c2020 [cited 2021 Apr 1]. Available from: https:// chicago.cbslocal.com/video/4510850-chicago-sees-an-uptickin-domestic-violence-calls-during-coronavirus-outbreak/.

11. Kruchevsky D, Arraf M, Levanon S, Capucha T, Ramon Y, Ullmann Y. Trends in burn injuries in Northern Israel during the COVID-19 lockdown. J Burn Care Res 2021;42:135-40.

12. Holmes S, Bhatti N, Bhandari R, Chatzopoulou D. Toward a consensus view in the management of acute facial injuries during the Covid-19 pandemic. Br J Oral Maxillofac Surg 2020;58: 571-6. 